\title{
Úlcera de membros inferiores na anemia falciforme
}

\section{Leg ulcers in sickle cell disease}

Silvia F. Paladino

\begin{abstract}
A úlcera de membros inferiores é uma complicação usualmente observada na doença falciforme. Ocorre com maior freqüência em pacientes SS do sexo masculino acima de 10 anos de idade. Seu aparecimento depende de vários fatores como o fenômeno de vaso-oclusão, hipóxia tecidual, hemólise, fatores genéticos e é inconclusiva a participação da insuficiência venosa na sua gênese. A cicatrização da úlcera é geralmente lenta e a taxa de recorrência é alta. Seu tratamento consiste em limpeza local e aplicação de produtos tópicos, como antibióticos, papaína, colágeno, entre outros. Podem-se utilizar medicamentos sistêmicos, transfusões periódicas e intervenção cirúrgica em casos especiais, mas não existe um consenso para a indicação de cada um deles. Não foram realizados estudos controlados e comparativos entre os diversos tipos de tratamento, a fim de se determinar qual a melhor conduta para as úlceras recorrentes ou refratárias. Rev. bras. hematol. hemoter. 2007;29(3):288-290.
\end{abstract}

Palavras-chave: Doença falciforme; genótipo; úlcera de perna; hidroxiuréia.

As úlceras de membros inferiores são complicações freqüentes em adultos com doença falciforme. Ocorrem entre $8 \%$ a $10 \%$ dos pacientes homozigotos, mas existem relatos de incidência maior de $50 \%$ em pacientes que residem em áreas tropicais. A variabilidade ocorre por diferenças genéticas e condições ambientais. São mais comuns em pacientes do sexo masculino, acima dos 10 anos de idade. Não há diferença na tendência de aparecimento nas diferentes estações do ano. , $^{1,6,7,8}$

Existe uma menor incidência de úlcera em pacientes SS com deleção de dois ou mais $\alpha$-genes do que nos pacientes que possuem três ou quatro $\alpha$-genes. São mais raras em pacientes SC e Sßtalassemia. ${ }^{1,3}$ Elas são dolorosas e podem ser únicas ou múltiplas. Ocorrem em áreas com menor tecido subcutâneo e pele fina, como a região maleolar interna ou externa, tibial anterior, área do tendão de Aquiles e em menor número no dorso do pé. Seu aparecimento pode ser espontâneo ou em conseqüência de pequenos traumas e atualmente não existe forma de prevenção. A recorrência é freqüente, a cicatrização é lenta e respondem pior ao tratamento do que as úlceras de outras etiologias. ${ }^{1,3,6,7}$

Existem várias teorias para explicá-las:

\section{Vaso oclusão}

O fenômeno de vaso-oclusão ocorre também em pele e provoca hipóxia tecidual e necrose da região do tornozelo. Os leucócitos e plaquetas participariam da vaso-oclusão, liberando fatores mediadores da inflamação capazes de promover a adesão da hemácia e do reticulócito ao endotélio, diminuindo o fluxo de sangue e provocando dano tecidual. ${ }^{2-5}$

\section{Fatores da coagulação e fibrinólise}

A deficiência de antitrombina III foi também implicada na patogênese da úlcera em pacientes falciformes, pois promove oclusão venosa. A participação de outros fatores ligados à coagulação, como os fatores XII, VII, a pré-calicreína, o D-dímero, no seu desenvolvimento ainda é incerta. ${ }^{2-5}$

\section{Haplótipos e hemoglobina fetal}

A incidência de úlcera é menor em pacientes que apresentam níveis elevados de $\mathrm{HbF}$ e hemoglobina. Níveis mais baixos de $\mathrm{HbF}$ estão relacionados à anemia mais intensa, o que agrava a hipóxia tecidual.

Os haplótipos estão associados à expressão do gene da $\gamma$-globina. Os pacientes com os haplótipos Senegal, Ára-

Médica assistente. Hospital Brigadeiro de São Paulo.

Correspondência: Silvia Filomena Paladino

Alameda Franca $n^{\circ}$ 519, apto11 - Cerqueira César

01422-000 - São Paulo-SP - Brasil

Tel.:(11)3284-1138

E-mail:hemoesp@terra.com.br 
be-indiano e Camarões apresentam níveis mais altos de hemoglobina fetal (HbF), enquanto o haplótipo CAR tem níveis mais baixos de HbF. O haplótipo Benin parece ter níveis intermediários. No Brasil predominam os tipos CAR segundo estudos publicados. $3,4,7,9$

\section{Inibição do óxido nítrico}

O óxido nítrico (ON) é um gás produzido pelo endotélio. É um potente regulador do tônus da musculatura lisa vascular, promovendo vasodilatação através do relaxamento da musculatura lisa do vaso. Controla a pressão do sangue e inibe a adesão plaquetária. Em condições fisiológicas o endotélio produz através da enzima óxido nítrico sintetase, pequenas quantidades de ON com meia-vida de cinco a dez segundos. A hemoglobina livre no plasma inativa o $\mathrm{ON}$ através da produção de meta-hemoglobina, nitrato e radicais livres. A hemólise intravascular está relacionada a uma depleção dos níveis de ON e a uma maior tendência à vasoconstrição. A presença de úlceras de membros inferiores em outras anemias hemolíticas sugere o papel da hemólise no seu desenvolvimento. . $^{2,10}$

\section{Genética}

A presença de genes polimórficos pode modular os subfenótipos da doença falciforme, levando a várias complicações, incluindo a úlcera. Os genes como o HLA-B35, Cw4 foram relatados nestes pacientes. Tem sido estudada a possível participação dos genes reguladores da enzima óxido nítrico sintetase e dos genes ligados à proliferação celular, resposta ao dano celular e angiogênese. ${ }^{3,6,11}$

\section{Insuficiência venosa}

O papel da hipertensão e da insuficiência venosa de membros inferiores na patogênese e persistência das úlceras é inconclusivo. ${ }^{3,12}$ As úlceras costumam ser rasas, com bordas sobrelevadas. É comum apresentarem exsudação e material necrótico na base. Com a cicatrização, a pele ao redor torna-se hiperpigmentada, com perda do tecido subcutâneo e folículos pilosos. A biópsia é inespecífica e revela hemácias falcizadas

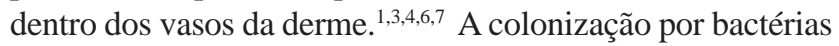
patogênicas é comum e algumas vezes pode haver infecção sistêmica, celulite, osteomielite e adenite regional. Pode ocorrer o adelgaçamento do córtex do osso na região da úlcera.

O uso de calçados macios e que se adaptem bem aos pés, o uso de repelentes para insetos, a hidratação da pele e o tratamento imediato de pequenos traumas são importantes medidas na tentativa de evitar que pequenos ferimentos se transformem em úlceras crônicas. ${ }^{1,3,6}$

Existem poucos estudos controlados e com poucos pacientes envolvidos. Geralmente são utilizadas técnicas para outros tipos de úlceras crônicas como as vasculares e as secundárias à diabete, sem comprovação da eficácia.

É importante que a equipe informe ao paciente que a possibilidade de cura e a menor recorrência dependem de sua adesão ao longo período de tratamento. Repouso e elevação do membro afetado por semanas ou meses são medidas efetivas, mas de pouca adesão. ${ }^{1}$

O tratamento tópico com antibióticos para o controle de infecções e a limpeza diária para retirada de material necrótico são medidas importantes para a cura. Deve-se evitar o uso prolongado de antibióticos tópicos, pois pode levar à colonização de germes resistentes. Como a circulação do sangue é deficiente na região, o uso de antibióticos sistêmicos só está indicado quando existirem sinais de infecção na pele sã ao redor da úlcera, como edema, hiperemia e exsudação excessiva. Está indicada a colheita de material para cultura e antibiograma. O paciente deve ser treinado para realizar a limpeza e o uso dos antibióticos tópicos ou dos curativos.

Existem estudos com a utilização de curativos variados como o liofilizado de pele de porco, a papaína, o colágeno, o mel, o hialuronato de sódio, entre outros. Estes curativos promovem um leve debridamento, auxiliando na remoção do material necrótico. Estes estudos foram realizados com poucos pacientes e vários curativos são de alto custo. . $^{1,3,6,7,9}$

O fator estimulante de crescimento de leucócitos e macrófagos - o GM-CSF tópico - foi utilizado com sucesso por alguns autores, mas também é de alto custo. ${ }^{17}$

A bota de Unna é uma opção de curativo quando o edema estiver controlado. Quando houver exsudação excessiva, deve ser trocada freqüentemente. Faixas elásticas podem ser utilizadas em conjunto com outros tratamentos para diminuir o edema. ${ }^{1,6} \mathrm{O}$ debridamento cirúrgico, o retalho miocutâneo por microcirurgia e o enxerto de pele parcial do próprio paciente podem ser realizados em úlceras grandes e refratárias aos tratamentos convencionais. Pode haver falha na pega do enxerto e recorrência após o período de repouso recomendado. ${ }^{1,3,6}$

Alguns autores sugerem que a HbS deve ser diluída abaixo de $50 \%$ com transfusões periódicas por um período mínimo de seis meses. Os riscos de infecção, aloimunização e acúmulo de ferro são grandes. Não existem estudos publicados que comprovem a eficácia das transfusões periódicas. ${ }^{1,3,6}$ Não foram realizados estudos controlados e comparativos entre os tratamentos convencionais e cirúrgicos, a fim de se determinar qual a melhor conduta para as úlceras recorrentes ou refratárias. ${ }^{1}$

A deficiência de zinco é comum na doença falciforme. O uso do sulfato de zinco nestes pacientes pode auxiliar na cura da úlcera. A dose recomendada é de $200 \mathrm{mg}$ três vezes ao dia por um período de seis meses. Não foram observados sinais de toxicidade. ${ }^{19} \mathrm{~A}$ hidroxiuréia teria um efeito benéfico pela redução do número de leucócitos e pelo aumento da $\mathrm{HbF}$, mas autores descreveram casos de aparecimento de úlcera em pacientes com doença mieloproliferativa e falciforme que tomaram a droga por longos períodos, mesmo em baixa dosagem. A hidroxiuréia inibe a duplicação celular da epiderme e talvez possa exacerbar a hipóxia tecidual na microcirculação. ${ }^{13,14} \mathrm{O}$ uso de pentoxifilina, L-carnatina, 
warfarina, butirato, eritropoietina e câmara hiperbárica foi relatado, mas seus resultados são ainda inconclusivos pelo pequeno número de pacientes em cada estudo., ${ }^{1,3,6}$ O concentrado de antitrombina III em associação com heparina foi utilizado com sucesso em um paciente com úlcera de perna, doença falciforme e deficiência de antitrombina III. ${ }^{6}$

A dor pode ser muito intensa com piora à noite. Requer o uso de analgésicos não opióides e opióides por via parenteral, oral ou adesivos cutâneos para seu controle. A aplicação de pomadas anestésicas antes da limpeza diminui a dor durante o curativo. Alguns autores relataram a aplicação de morfina ou oxicodona tópicas associadas ou não com anestésicos tópicos, obtendo-se boa resposta. ${ }^{1,3,4,6,18}$

\section{Recomendações}

O tratamento indicado para todos os pacientes é a realização de limpeza da úlcera diária, o repouso e a elevação do membro afetado. A utilização de curativos, de tratamentos cirúrgicos, medicações excepcionais ou transfusões deve ser considerada a cada caso. O uso de antibióticos sistêmicos só está indicado em infecção da pele sã ao redor da úlcera. Os cuidados com calçados, picadas de insetos, higiene e hidratação da pele são importantes para a prevenção ou recorrência. O controle da dor pode ser feita com analgésicos não opióides e opióides por via parenteral, oral e adesivos cutâneos. A aplicação de pomadas anestésicas antes da limpeza diminui a dor durante o curativo.

\section{Abstract}

Leg ulcers are a common cutaneous manifestation in sickle cell disease. They are more common in homozygous patients (SS) and in over 10-years-old male patients. Their development depends on several factors such as the vaso-occlusion phenomenon, tissue hypoxia, hemolisis and genetic factors. Venous incompetence may play a role in their pathogenesis and persistence. Topical treatment and elevation of the affected leg are recommended. Dressings, surgical interventions, transfusions and systemic medications are used in special cases. There have been no studies published comparing the different therapies and their efficacies. Rev. bras. hematol. hemoter. 2007;29(3):288-290.

Key words: Sickle cell; genotype; leg ulcer; hydroxiurea.

\section{Referências Bibliográficas}

1. The Management of Sickle Cell Disease - NIH Institutes of Health - National Heart, Lung and Blood Institutes - Division of Blood Diseases and Resources. $4^{\text {th }}$ edition. Leg ulcer., 2002. p. 139.

2. Telen MJ, Kaufman RE. The mature erythrocyte. In: John Greer, John Foerster, John Lukens, George Rodgers, Frixos Paraskevas, Bertil Glader. Wintrobe's Clinical Hematology. 11 ${ }^{\text {th }}$ edition, 2004; v.1 p.217.

3. Wang WC. Sickle cell anemia and other sickling syndromes. In: John Greer, John Foerster, John Lukens, George Rodgers, Frixos Paraskevas, Bertil Glader. Wintrobe's Clinical Hematology. $11^{\text {th }}$ edition, 2004, v.1 p. 1263.
4. Costa FF. Anemia falciforme. In: Marco Antonio Zago, Roberto Passeto Falcão, Ricardo Pasquini (editores). Hematologia: fundamentos e prática. Editora Atheneu, 2004. p.239.

5. Morelli VM. Estrutura de funções das plaquetas e das células endoteliais. In: Marco Antonio Zago, Roberto Passeto Falcão, Ricardo Pasquini (editores). Hematologia: fundamentos e prática. Editora Atheneu, 2004. p.731.

6. Trent JE, Kirsner RS. Leg ulcer in sickle cell disease. Advances in Skin \& Wound Care. 2004;17(8):410.

7. Koshy M, Entsuah R, Koranda A, Kraus AP, Johnson R, Bellvue R, et al. Leg ulcer in patients with sickle cell disease. Blood. 1989;74(4):1403.

8. Powars DR, Chan LS, Hiti A, Ramicone E, Johnson C. Outcome of sickle cell anemia - A 4-decade observational study of 1056 patients. Medicine. 2005;84(6):363.

9. Eckman JR. Leg ulcer in sickle cell disease. Hematology Oncology Clinics North America. 1996;10:1333.

10. Kato G, McGowan V, Machado R, Little JA, TaylorVI J, Morris CR et al. Lactate dehydrogenase as biomarker of hemolisis-associated nitric oxide resitance, priapism, leg ulceration pulmonary hypertension, and death in patients with sickle cell disease. Blood. 2006;107(6):2279.

11. Nolan VG, Adewoye A, Baldwin C, Wang, L, Ma Q, Wyszynski D et al. Sickle cell leg ulcer: associations with haemolysis and SNPs in Kltho, TEK and genes of the TGF-ß/BMP pathway. British Journal of Haematology. 2006;133:570.

12. Clare A, Fitzhenley M, Harris J, Hambleton I, Serjeant GR. Chronic leg ulceration in homologous sickle cell disease: the role of venous incompetence. British Journal of Haematology. 2002;119:567.

13. Saxena R, Batra VV, Ahmed RPH. Hydroxiurea and sickle cell leg ulcer. American Journal of Hematology. 2001;68:215.

14. Best PJ, Daoud MS, Pittelkow, MR, Petitt RM. Hydroxiureainduced leg ulceration in 14 patients (brief communications). Annals of Internal Medicine. 1998;128(1):29.

15. Zago MA, Figueiredo MS, Ogo SH. Bantu $\aleph^{\text {S }}$ cluster haplotypes predominates among Brasilians blacks. American Journal Physiology and Anthropology. 1992;88:295.

16. Gualandro SFM, Yokomozo IK, Chamone DAF, Krieger JE. Determination of ß-like gene cluster haplotypes and prevalence of $\alpha$-thalassemia in a popoulation of sickle cell anemia patients in Brazil, correlation with fetal hemoglobin levels. Internal Journal of Hematology Abstracts v. 64 p. S81,1996 (Apresentado no 26th Congress of International Society of Hematology, Singapore, !996)

17. Shear, GD, Olivieri NF. Rapid healing of chronic leg ulcer during arginine butyrate therapy in patients with sickle cell disease and thalassemia. Blood. 1994;84:2378.

18. Steinberg MH. Management of sickle cell disease. New England Journal of Medicine. 1999;340(13):1021.

19. Méry L, Girot R, Aractingi S. Topical Effectiveness of Molgramostim (GM-CSF) in sickle cell leg ulcer. Dermatology. 2004;208:135.

20. Alikhan MA, Carter G, Mehta P. Topical GM-CSF Hastens Healing of leg ulcers in sickle cell disease. American Journal of Hematology. 2004;76:192.

21. Ballas S. Treatment of painful sickle cell leg ulcer with topical opiods. Blood. 2002;99(3):1096.

22. Serjeant GR, Galloway RE, Gueri MC. Oral zinc sulphate in sicklecell ulcers. The Lancet. 1970;2:891.

O tema apresentado e o convite ao autor constam da pauta elaborada pelo co-editor, prof. Rodolfo Delfini Cançado.

Avaliação: Co-editor e um revisor externo.

Publicado após revisão e concordância do editor.

Conflito de interesse: não declarado.

Recebido: 13/04/2007

Aceito: 27/05/2007 